\title{
Simple induction and assessment of barbiturate physical dependence in the rat
}

\author{
RICHARD LETZ and J. K. BELKNAP \\ University of Texas at Austin, Austin, Texas 78712
}

\begin{abstract}
Physical dependence to phenobarbital via an oral ingestion method was demonstrated in rats. Also, the utility of air-puff-elicited startle for assessing both intoxication and withdrawal effects was shown. Avoidance of phenobarbital-adulterated food was enhanced as a result of prior exposure to chronic phenobarbital intoxication and subsequent withdrawal.
\end{abstract}

Studies of drug dependence have been hampered by the lack of suitable methods for producing voluntary ingestion of intoxicating quantities of drugs by laboratory animals. Barbiturate dependence has been produced most frequently and most handily in laboratory animals by using the method of Crossland and Leonard (1963), i.e., to mix gradually increasing doses of sodium barbital in the animal's drinking water. Unfortunately, this procedure must be used for a period ranging from 5 weeks (Leonard, 1967, 1968) to 111 days or more (Essig, 1966), and saccharin must also be added to the drug-adulterated water to make it more palatable to the animals.

Recently, Belknap, Waddingham, and Ondrusek (1973) have readily demonstrated barbiturate physical dependence in mice via a simple oral ingestion method. The animals were fed a milled diet adulterated with phenobarbital. Because the behavior of the rat has been more studied than that of the mouse, a similar method for producing physical dependence in the rat would be useful in attacking problems concerning behavioral, neurophysiological, and neurochemical correlates of physical dependence.

Objective methods used to assess the behavioral effects of withdrawal have usually involved seizure thresholds to electroconvulsive shock or chemical convulsants (Leonard, 1968), seizure thresholds to auditory stimulation (Crossland \& Turnbull, 1972), and performance in a maze (Leonard, 1967). Unfortunately, repeated exposure to the evaluation procedure is necessary to detect changes, and confounding cumulative effects undoubtedly occur with repeated exposure to the above traumatic procedures.

In a study of ethanol dependence using the rat, Gibbons, Kalant, LeBlanc, and Clark (1971) used a startle response measure to footshock to assess withdrawal effects. Galvani (1970) has indicated that

This research was supported in part by a grant from the Weight Watchers Foundation to Dr. D. Singh and in part by NSF-USDP GU-1598 to Dr. J. Belknap. The authors wish to express their deep appreciation to Dr. Singh. Requests for reprints should be sent to Richard Letz, Mezes Hall 330, Department of Psychology, The University of Texas at Austin, Austin, Texas 78712 . habituation to air-puffelicited startle does not occur in the rat. Work in our own laboratory has shown that a decrement in air-puffelicited startle occurs only after the initial exposure to the procedure (Singh, Letz, Miller, Note 1). It would seem that air-puff-elicited startle would be a useful method for assessing the effects of intoxication and withdrawal.

Therefore, the present study was undertaken to demonstrate physical dependence in the rat via an oral ingestion method and to monitor the effects by an objective behavioral measure (startle response). Other questions were also asked. Assuming that physical dependence could be demonstrated, would rats show a preference for food causing intoxication, would they avoid it, or would they be indifferent to it? And would this pattern change as a result of physical dependence and withdrawal?

\section{METHOD}

Ten female Sprague-Dawley rats, 300 days old, weighing $290-350 \mathrm{~g}$ were used. The subjects had been used previously as experimental controls in an appetitive conditioning experiment. All subjects were housed in individual stainless steel cages in a colony room having a 12 -h light-dark cycle. Water was available ad lib throughout the experiment.

Two foodcups were always available with milled Purina Rat Chow. The drug diet consisted of the milled diet adulterated with $2.5 \mathrm{mg}$ of powdered phenobarbital (Sigma Chemical Company) per gram of milled diet. Pilot work had shown that this concentration produced greater intoxication than $2.0 \mathrm{mg} / \mathrm{g}$ and that $3 \mathrm{mg} / \mathrm{g}$ resulted in illness and serious loss of weight.

The startle stimulus was a 10 psi puff of air delivered from a standard cylinder of compressed air, through a solenoid valve (Alco Controls), through $2 \mathrm{~m}$ of $3 / 8$ in. vinyl tubing to the side of an $11 \times 13 \times 12 \mathrm{~cm}$ wooden chamber in another room. The solenoid valve was opened for $200 \mathrm{msec}$ by a variable interval timer. The chamber, too small for the subject to avoid the puff of air, was suspended $2 \mathrm{~mm}$ above a $30 \mathrm{~cm} \mathrm{x} 30 \mathrm{~cm} \times 3.5 \mathrm{~mm}$ plastic plate. The corners of the plate were anchored to $5-\mathrm{cm}$-tall rubber stoppers, and a steel pole was attached to the center. Depression of the center of the plate changed the position of the pole within a coil (Elgin National Watch Company, Advanced Relays GHA-2C) anchored below and altered its output. The coil was wired through a GSR preamplifier to a physiograph channel amplifier and rectilinear pen motor (E\&M Instrument Company). The amount of pen deflection was directly proportional to the amount of force against the plastic plate. 


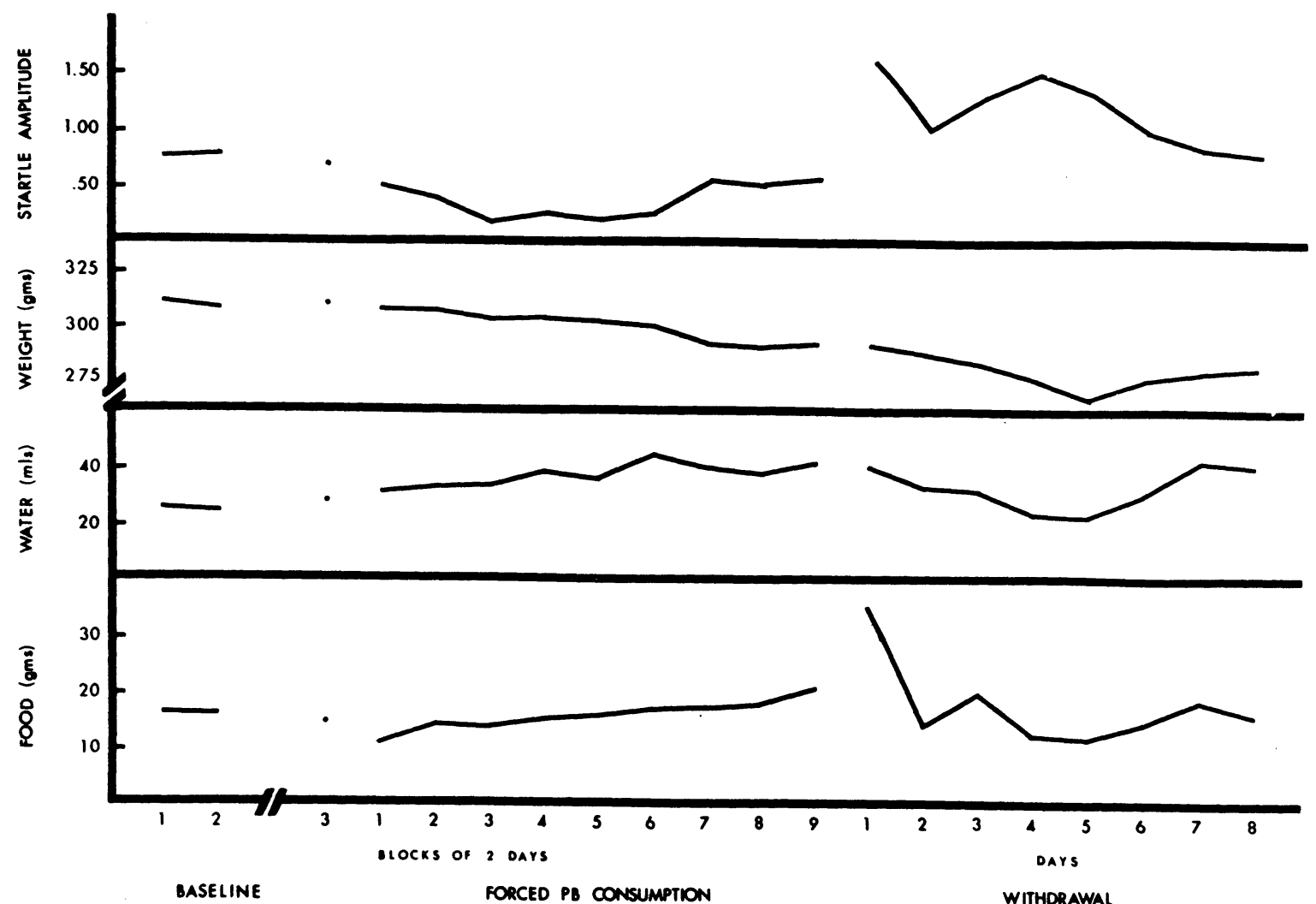

Figure 1. Mean food, water, weight, and startle index for baseline, forced PB consumption, and withdrawal periods. Each point for food, water, and weight during the baseline and forced PB consumption periods represents means of 2-day blocks. All other points represent the group's mean for a single day.

Food, water, and weight data were taken once daily along with a brief period of individual observation throughout the experiment. The time course of the experiment was as follows: 2 weeks habituation to the milled diet (regular milled chow available in both foodcups), a preference test [10 days of phenobarbital (PB) adulterated food available in one cup and regular chow in the other], a second baseline period ( 2 days), 18 days of forced PB consumption (PB-adulterated chow available in both cups), 8 days of forced withdrawal (regular milled chow in both cups), followed by a second preference test ( 5 days). During the preference tests, the initial placement of the PB-adulterated food was counterbalanced according to each animal's position preference, and the placement was random thereafter.

Periodically, the rats were given air-puff-elicited startle sessions: two baseline sessions, every 2 nd day during the forced PB consumption period and every day during the withdrawal period. A puff of air was delivered to the subject on the average of every $30 \mathrm{sec}, 10$ times per session. The amount of physiograph pen deflection was divided by the mass of the animal to yield its acceleration. This index was summed over the 10 trials to yield a startle index for each animal for each session.

All statistical analyses were performed using a repeated measures analysis of variance computer program (Dixon, 1971).

\section{RESULTS}

The behavioral symptoms observed during intoxication and withdrawal were similar to those reported for sodium barbital in rats (Essig, 1966). In addition, they were similar to those observed for PB in mice (Belknap et al., 1973) and for ethanol in rats
(Hunter, Boast, Walker, and Zornetzer, 1973), although the time course was much slower. Daily observations revealed signs of gross intoxication such as ataxia and loss of coordination on the 1 st day after forced PB consumption began. Severe intoxication continued throughout the forced PB consumption period. One animal died of an apparent overdose of PB $(75 \mathrm{mg} / 24 \mathrm{~h})$ on the 18th day of forced PB consumption. Animals were often found comatose with their heads still in the foodcups.

During the forced withdrawal period, there was an initial transient period of hyperactivity followed by gross hypoactivity which gradually returned to normal. The initial hyperactivity accelerated a respiratory infection in one animal, and it died on the 1st day of withdrawal. Tremors and ataxia developed following the onset of hypoactivity and were followed by rigidity and hyperreactivity. Seizures were aduitorily induced (jingling of keys) in three of the eight animals on the 3rd day of withdrawal. On the gross behavioral level, no withdrawal effects were evident after the 5 th day of the withdrawal period, with the exception of a tendency to hyperreact to sudden noises.

Figure 1 shows the food, water, and weight and startle data for the forced PB consumption and withdrawal periods of the experiment. Food intake was subnormal at the beginning of forced $\mathrm{PB}$ consumption but increased steadily throughout the 18-day period $(F=6.7$, 
$\mathrm{df}=17 / 153, \mathrm{p}<.001)$. Water intake showed a corresponding increase, but it was never subnormal. Body weight, usually stable at this age, declined about $5 \%$ throughout the forced PB consumption period. The steadily increasing food consumption maintained the previously noted severe intoxication levels throughout this period. PB consumption increased from a mean of approximately $79 \mathrm{mg} / \mathrm{kg} /$ day on the $1 \mathrm{st}$ day of consumption to a mean of $177 \mathrm{mg} / \mathrm{kg} /$ day on the last day $(F=8.2, \mathrm{df}=17 / 153, \mathrm{p}<.0001)$. Startle amplitude showed a significant decrease from baseline throughout the forced $\mathrm{PB}$ consumption period $(\mathrm{F}=10.8, \mathrm{df}=1 / 9$, $\mathrm{p}<.01$ ), beginning $24 \mathrm{~h}$ after $\mathrm{PB}$ was introduced. It reached its lowest point on the 5 th day, then returned toward baseline levels.

During the 1st day of withdrawal, two drastic changes occurred: every subject showed an increase in food intake above the previous day's supernormal amount (20.5 to $35.5 \mathrm{~g}$, mean increase $=78 \%, F=13.2, \mathrm{df}=1 / 7$, $\mathrm{p}<.009)$ and an increase in startle amplitude from previous day's value (mean increase $=171 \%, F=30.8$, $\mathrm{df}=1 / 7, \mathrm{p}<.0009$ ) to over twice its baseline value $(\mathrm{F}=29.6, \mathrm{df}=1 / 7, \mathrm{p}<.001)$. Both these changes were followed by large decreases on the 2 nd day of withdrawal with rebounds on the 3 rd day. Food intake then decreased to the 5 th day and increased to the end of the withdrawal period. Water intake showed roughly the same changes except that the drastic increase did not occur on the 1 st day. Body weight continued to decline as it had during the forced $\mathrm{PB}$ consumption period until the 5 th day of the withdrawal period, when it began increasing.

The most interesting data in Figure 1 are the startle data. The data for the forced consumption period readily indicate the intoxication effects and correspond with the gross behavioral observations. The initial drastic increase in startle amplitude during withdrawal corresponded to the transient general hyperactivity and the drastic increase in food intake. The sharp drop on the 2nd day corresponded with the onset of general hypoactivity and the drop in food intake. But on the $3 \mathrm{rd}$ and 4th days, startle amplitude increased again, corresponding to the appearance of auditory-induced seizures. Thus, the animals became hyperreactive while remaining hypoactive. In addition, during the last 3 days of the withdrawal period, the startle amplitude remained supernormal, corresponding to the observed sensitivity of the animals to sudden noises, while the animals' gross activity levels had returned to normal.

Table 1 shows the results of the two preference tests. It shows a gradual development of avoidance of PB-adulterated food in the initial test and a much more rapidly developing avoidance in the second test $(F=11.5, \mathrm{df}=1 / 9, \mathrm{p}<.008)$. The animals did not avoid the taste of the PB until its intoxicating effects manifested themselves, and this avoidance of $\mathrm{PB}$ consumption was enhanced after $\mathrm{PB}$ consumption and withdrawal.
Table 1

Phenobarbital-Adulterated Food Consumed (Mean Percentage of Total) During Preference Tests

\begin{tabular}{ccc}
\hline Day & $\begin{array}{c}\text { Before Forced } \\
\text { Consumption }\end{array}$ & $\begin{array}{c}\text { After } \\
\text { Withdrawal }\end{array}$ \\
\hline 1 & 30.1 & 29.4 \\
2 & 15.4 & 7.5 \\
3 & 12.8 & 2.4 \\
4 & 8.1 & 2.3 \\
5 & 5.7 & .6 \\
6 & 6.4 & - \\
7 & 6.4 & - \\
8 & 4.1 & - \\
9 & 1.4 & - \\
10 & 1.2 & - \\
\hline
\end{tabular}

\section{DISCUSSION}

The results are in agreement with others reported for barbiturates (Essig, 1970). A simple reliable method of producing physical dependence in the rat has been demonstrated. This oral ingestion method appears to be superior to other methods presently available because: (1) it requires little effort, (2) it involves no trauma to the animal, (3) it requires a shorter period of time to induce physical dependence, and (4) the drug is readily consumed without the need to mask an aversive taste.

In addition, air-puff-elicited startle has been demonstrated to be a sensitive reliable method of assessing intoxication and withdrawal effects in rats. This measure is especially useful because: (1) it is objective; (2) it involves no trauma to the animal; (3) it can be used repeatedly; and, most importantly, (4) it can be used to assess the effects of both intoxication and withdrawal.

Finally, it has been shown that rats will avoid PB consumption as a function of previous exposure. It is not likely that the avoidance was due to the aversive taste properties of the $P B$, because the animals ate substantial amounts of PB-adulterated food on the 1st day of each preference test. Belknap et al. (1973) have reported that mice show little reluctance to ingest an identical PB diet in similar preference tests. Only when the intoxicating effects became evident (late in the 1st day) and when the consequences of such effects became apparent (i.e., after forced PB consumption and withdrawal) did the animals completely avoid the PB-adulterated food.

The induction of physical dependence to a long-acting depressant drug in the rat via an oral ingestion method should provide a simple tool for investigating many questions concerning tolerance and physical dependence. It should prove useful for investigating a multitude of biochemical, neurophysiological, and behavioral (e.g., motivational and associative) questions in a much-studied animal.

\section{REFERENCE NOTE}

Singh, D., Letz, R., \& Miller, J. Emotionality in ventromedial hy pothalamically lesioned rats. In preparation. 


\section{REFERENCES}

Belknap, J. K., Waddingham, S., \& Ondrusek, G. Barbiturate dependence in mice induced by a simple short-term oral procedure. Phy siological Psy chology, 1973, 1, 394-396.

Crossland, J., \& Leonard, B. Barbiturate withdrawal convulsions in the rat. Biochemical Pharmacology, 1963, 12, 103 (suppl.).

Crossland, J., \& Turnbull, M. J. Gamma-aminobuty ric acid and the barbiturate abstinence syndrome in rats. Neuropharmacology, 1972, 11, 733-738.

Dixon, W. J. BMD08V in Biomedical Computer Programs (2nd ed.). Los Angeles: University of California Press, 1971.

Essig, C. Barbiturate withdrawal in white rats. International Journal of Neuropharmacology, 1966, 5, 103-107.

Essig, C. Barbiturate dependence. In: R. Harris, W. McIsaac, and C. Shuster (Eds.), Drug dependence. Austin: University of Texas Press, 1970.

Galvani, P. F. Air-puffelicited startle: Habituation over trials and measurement of a hypothetical emotional response. Behavior Research Methods \& Instrumentation, 1970, 2, 232-233.
Gibbins, R. J., Kalant, H., LeBlanc, A. E., \& Clark, W. The effects of chronic administration of ethanol on startle thresholds in rats. Psychopharmacologia (Berl.), 1971, 19, 95-104.

Hunter, B. E., Boast, C. A., Walker, D. W., \& Zornetzer, S. F. Alcohol withdrawal syndrome in rats: Neural and behavioral correlates. Pharmacology, Biochemistry and Behavior, 1973, 1, 719-725.

Leonard, B. E. The effect of chronic administration of barbitone sodium on the behavior of the rat. International Journal of Neuropharmacology, 1967, 6, 63-70.

Leonard, B. E. The effect of chronic administration of sodium barbitone on chemically and electrically induced convulsions in the rat. International Journal of Neuropharmacology, 1968, 7, 463-468.

(Received for publication March 4, 1975; accepted March 12, 1975.) 